\title{
Divided Loyalists or Conditional Cooperators? Creating Consensus about Cooperation in Multiple Simultaneous Social Dilemmas
}

\author{
Matthew W. McCarter \\ Department of Management \\ University of Texas - San Antonio \\ and Economic Science Institute \\ Anya C. Samak \\ Department of Human Ecology \\ University of Wisconsin - Madison \\ Roman M. Sheremeta \\ Department of Economics \\ Case Western Reserve University \\ and Economic Science Institute
}

\begin{abstract}
The current social dilemma literature lacks theoretical consensus regarding how individuals behave when facing multiple simultaneous social dilemmas. The divided-loyalty hypothesis, from organizational theory, predicts that cooperation will decline as individuals experience multiple social dilemmas with different compared to the same group members. The conditional-cooperation hypothesis, from behavioral economics, predicts that cooperation will increase as individuals experience multiple social dilemmas with different compared to the same group members. We employ a laboratory experiment to create consensus between these literatures and find support for the conditional-cooperation hypothesis. The positive effect of interacting with different group members comes from participants having an opportunity to shift their cooperative behavior from the less cooperative to the more cooperative group.
\end{abstract}

$($ Abstract word count $=115)$

Keywords: cooperation, conditional cooperation, defection, loyalty, experiments, public goods, social dilemmas 
A parent of an honors student involves himself simultaneously on the boards of his son's Boy Scout Troop and the neighborhood Homeowners' Association. Each week he must decide how much time to allocate between these two groups' activities.

There are a few things that most of us find familiar with this vignette. First, it is often the case that the benefits enjoyed in organizations come from the aggregated cooperative behavior of individuals (Aquino \& Reed, 1998). The catch is that cooperative behavior when organizing creates a social dilemma (Dawes, 1980; Ferrin, Bligh, \& Kohles, 2007). A social dilemma is an interdependent decision-making situation where "individually reasonable behavior leads to a situation in which everyone is worse off than they might have been otherwise" (Kollock, 1998, p. 183). The social dilemma of organizing is that resources must often be pooled from individuals to create synergistic shared benefits but, once produced, these benefits can be enjoyed by everyone whether or not their resources were pooled (Olson, 1965). Consequently, an individual may choose to not pool her resources; but, if everyone follows this strategy then the synergistic shared resources do not materialize.

A second thing we may find familiar in this vignette is that we are often involved in multiple social dilemmas simultaneously. For three decades scholarship in management, public policy, and economics has discussed the idea of cooperation in multiple simultaneous social dilemmas (Cross \& Guyer, 1980; Janssen \& Ostrom, 2006) with empirical work beginning to emerge. The burgeoning work includes Falk and colleagues' (2013) laboratory experiment about social interaction when participating in multiple social dilemmas with different group members. Relatedly, another collection of papers investigate decision-making in multiple different environments, but not multiple social dilemmas (Bednar, Chen, Liu, \& Page, 2012; Cason, Savikhin, \& Sheremeta, 2012; McCarter \& Sheremeta, 2013; Savikhin \& Sheremeta, 2013). We 
are left with the question: what effect does facing multiple social dilemmas simultaneously with same rather than different fellow group members have on cooperation?

When we turn to the current literature, however, a confusion gap is found (Sandberg \& Alvesson, 2011): there are competing predictions about how individuals should behave in multiple simultaneous social dilemmas depending on the group's structure. The divided-loyalty hypothesis predicts that cooperation will decline as individuals experience multiple simultaneous social dilemmas with different compared to the same group members (McCarter \& Northcraft, 2007). The conditional-cooperation hypothesis predicts that cooperation will increase as individuals experience multiple simultaneous social dilemmas with different compared to the same group members (Fischbacher, Gächter, \& Fehr, 2001). Using a randomized laboratory experiment, we seek to "create consensus" (Hollenbeck, 2008) by testing these competing hypotheses. In support of the conditional-cooperator hypothesis, we find greater cooperation when individuals face multiple social dilemmas with different group members compared to with the same group members. The positive effect of interacting with different group members comes from participants having an opportunity to shift their cooperative behavior from the less cooperative to the more cooperative group.

Our findings make several contributions to research about social dilemmas and social cooperation. Complementing traditional scholarship examining discretion over how resources are allocated between self- and collective interests, we consider a different way individuals have discretion when attempting collective action: choosing which collective action to undertake. Further, we provide preliminary support for the Simonic approach to social cooperation (Simon, 1996). Contrary to the Hardinic approach (Hardin, 1968) that assumes exploiters in an organizational system will persist to the point where cooperators give up and the system fails, we 
find that cooperators do not give up but, as Simon (1996) would suggest, rather "vote with their feet" to achieve cooperation. Lastly, our findings hold practical significance for policymakers and managers: organizing individuals to attempt collective action with different groups (compared to the same groups) may increase cooperation by over $50 \%$.

\section{Theoretical Background and Hypotheses}

\section{Social Dilemmas: A Brief Review}

Social dilemmas come in a variety of forms (Dawes, 1980). As outlined in Messick and Brewer's (1983) seminal review, social dilemmas often involve contributing resources. The most common example of a social dilemma about contributing resources is the public goods dilemma (Samuelson, 1954). Public goods are resources that can be enjoyed by everyone regardless of contribution level; moreover, each individual's enjoyment of the public good does not subtract from others' enjoyment (Olson, 1965). Organizational examples of public goods provision include investment in community organizations (e.g., Boy Scouts and home owner associations), charitable giving to the non-profit sector (e.g., gifts to the Red Cross) and the impact of generic advertising on sales in a particular industry (e.g., 'Got Milk' campaigns).

Non-contributors may benefit equally from the public good, creating an individual temptation not to contribute. Due to this temptation, public goods often struggle to be produced (Yamagishi \& Sato, 1986). This gives rise to the public-goods social dilemma (henceforth public goods dilemma). In public goods dilemmas, individuals can cooperate by contributing private resources to produce the public good, but they can also defect by not contributing toward the public good (Zeng \& Chen, 2003). In addition to the temptation to under-contribute toward the public good, individuals more often under-contribute defensively (McCarter, Rockmann, \& Northcraft, 2010): they fear that others will free ride on their contributions (Rockmann \& 
Northcraft, 2008). Consequently individuals contribute more toward the public good when they know that others are also contributing (Fischbacher et al., 2001).

\section{Multiple Simultaneous Social Dilemmas: A Confusion Gap in the Literature}

The majority of social dilemma scholarship about public goods examines cooperation and defection behavior in the context of producing a single public good (Van Lange, Joireman, Parks, \& Van Dijk, 2013). However, as suggested in Cross and Guyer's (1980) book on social dilemmas, many organizational public goods dilemmas are interconnected, whereby an individual faces multiple dilemmas simultaneously. Current social dilemma research has given little empirical attention to this observation made over 30 years ago. Further, current social dilemma research is divided about predicting patterns of cooperation behavior in multiple simultaneous, public goods dilemmas. This division is between the divided loyalties prediction maintained from organizational theory and the conditional cooperation prediction from behavioral economics.

\section{Divided-loyalist Hypothesis}

Social dilemma scholarship in organization behavior and management observes that individuals can be nested simultaneously within multiple groups who are all facing a social dilemma (Polzer, Stewart, \& Simmons, 1999; Wit \& Kerr, 2002). As predicted by McCarter and Northcraft (2007), belonging to multiple groups with different members may create a tension of allegiances, encouraging an individual to "fear [their partner's] interests no longer rest with only [their group] but with other [groups]" (p. 504). As a consequence of the potential for divided loyalties, an individual is motivated to protect her private resources and defensively undercontribute toward the public good. Scholarship advocating the divided loyalty position would 
predict that, compared to facing multiple social dilemmas with the same people, facing multiple social dilemmas with different people may lead an individual to question the others' allegiance. When comparing same versus different group membership structure, the divided-loyalist hypothesis would be:

Hypothesis 1: Individuals will contribute less toward multiple public goods when involved in different groups as compared to individuals involved in the same group.

\section{Conditional-cooperation Hypothesis}

Behavioral economics research on conditional cooperation in social dilemmas makes a different prediction based on the observation that individuals cooperate more (less) the more (less) others cooperate (Fischbacher et al., 2001; Gächter, 2007). Ichino and Maggi’s (2000) field study on shirking behavior finds that an individual's contribution towards a group's interest is a function of how others in the group behave (also termed social [or group] interaction). In considering the strong normative influence often imposed on an individual by a group (Deutsch

\& Gerard, 1955), working with different groups on related tasks (as compared to with the same group) provides flexibility not only in where to allocate resources but also with whom individuals work (O’Leary, Woolley, \& Mortensen, 2011).

Based on this body of work, an alternative prediction to the current research question would be that being a member of two groups composed of different participants increases the likelihood that conditional cooperators will be able to sustain cooperation (at least in one group that is more cooperative). The increase in likelihood of having more cooperators in one of the two groups increases the likelihood of others following a cooperative signal. In addition, conditional cooperators participating in two groups with different fellow group members may use the lower-cooperating group as a reference point with which to compare the higher- 
cooperating group, always contributing more to the higher-cooperating group. In contrast, conditional cooperators participating with the same group members do not have this reference point since they know that the level of pro-sociality of fellow members across groups should be the same (group members in both public goods games are inherently the same type - cooperative or not). Thus, we propose the following alternative hypothesis:

Hypothesis 2: Individuals will contribute more toward multiple public goods when involved in different groups compared to individuals involved in the same group.

\section{Method}

\section{Overview of the Experimental Approach}

We tested our hypotheses using a laboratory experiment. Like any research examining social behavior, we had to make tradeoffs between generalizability, accuracy and simplicity (Thorngate, 1976). Each of these elements affects the external and internal validity of our findings (Cook \& Campbell, 1979). Laboratory experiments have high internal validity, thus providing us with great accuracy in measuring the treatment effect on cooperation (Creswell, 2008). Further, laboratory experiments provide for the ability to draw straightforward conclusions when explaining the relationship between treatment and cooperation. Laboratory experiments, however, can be susceptible to low external validity and hence generalizability (Creswell, 2008). We chose to use a laboratory experiment because - rather than focusing on the ecological validity of context, our research focuses on creating "experimental realism" (Berkowitz \& Donnerstein, 1982). That is, we were interested in making the relationship between cooperation and treatment the focus of the work. 


\section{Experimental Design and Procedure}

The study was conducted at a large public university in the Central United States and involved a randomized experiment where the group structure variable had two treatments: Same and Different. In the Same treatment, two public goods dilemmas were played simultaneously by each individual with the same group members in each public goods dilemma. In the Different treatment, two public goods dilemmas were played simultaneously by each individual with one set of group members in one of the public goods dilemmas and a set of different group members in the other public goods dilemma.

Participants were recruited from a pool of undergraduate students (who are recruited from courses across the entire campus, and thus represent many different majors). A total of 104 individuals participated in 6 sessions, with 40 individuals participating in 2 sessions of the Same treatment (20 participants per session) and 64 individuals participating in 4 sessions of the Different treatment (16 participants per session). Our randomized experiment utilized the procedures outlined by Friedman and Sunder (1994, p. 26) and Cassar and Friedman (2004, p. 35). We scheduled 4 sessions over the course of 2 days, and assigned each session to either Same or Different, balancing by time of day. Then, since the design required additional sessions of Different, we scheduled 2 more sessions on another day and assigned those to Different. Schedules were assigned to treatment prior to seeing which students came in, and eligible students were notified via email to sign up. To randomize students across treatments, we used a computer software program (ORSEE) to randomly select eligible students from the subject pool for each session and solicit their participation by email (Greiner, 2004). A participant only received solicitation for one session. Participants received monetary incentives, but not course credit, for participating. 
Similar to our Same treatment, existing studies consider simultaneous interaction in several public goods, either breaking a single public good into parts or presenting multiple public goods. Bernasconi and colleagues (2009) investigate an "unpacked" public goods dilemma, comparing contributions when a single group contributes to one public goods dilemma as compared to multiple public goods dilemmas, and find that contributions are greater under the unpacked treatment, although this increase is not sustained for the duration of the session. Biele and colleagues (2009) break up 4-person groups into two 2-person groups, and find that participants contribute more in the smaller groups. Similar to our Different treatment, Falk and colleagues (2013) investigate contributions in groups of different individuals playing two identical public goods dilemmas.

The main difference of our study as compared to previous work is that we investigate simultaneous decision-making both with different and the same group members under a shared budget constraint. The direct comparison of same versus different group members allows us to expose participants to a controlled set of fellow group members in order to better understand the role of conditional cooperation. This is the first study to consider the effect of social interactions when groups are different or the same. Unlike most work in this area, our experiment uses a shared budget constraint, effectively allowing participants to shift their entire endowment to just one of the public goods. This aspect of the design is also more realistic, because in practice individuals participate in many environments simultaneously and are constrained by a single budget constraint when choosing between various activities.

The computerized experimental sessions used z-Tree (Fischbacher, 2007) to record participants' decisions and also to record the order of decisions. Participants were given the instructions, shown in the appendix, at the beginning of the session and the experimenter read the 
instructions aloud. In each session of the Same treatment, 20 participants were randomly assigned to a group of 4 players, and played both games with the same group members. In each session of the Different treatment, 16 participants were randomly assigned to a group of 4 players in one game and to a different group of 4 players in the other game, such that no participants played one game with any of their group members from the other game. Group composition remained fixed for all 20 rounds of the experiment in both treatments. All participants participated in only one session of this study.

In each round, the two public goods dilemmas were displayed side by side on the same screen. Figure 1a displays the screens participants saw for the Different treatment, and Figure 1b displays the screens participants saw for the Same treatment. At the beginning of each round, each participant received an endowment of 160 experimental francs, which could be transferred between public goods. Each participant chose a portion of the endowment to contribute to one or both of the public goods, and chose to keep the remaining portion in a private account. Each player's contribution to the public good was multiplied by 0.4 and the total of all contributions given to each of the 4 players in the group in each public goods dilemma. Each participant kept the remainder of the 160-franc endowment that he did not allocate to either public good. Participants did not know others' decisions before making their own decisions. After all participants made their decisions, the sum of all contributions in each group was displayed on the output screen together with the outcome, and earnings in each round were determined as the sum of the endowment kept in the private account and the earnings from the public goods. Participants recorded their results in a record sheet, and then moved on to the next round.

At the end of the experiment, two rounds from the game were selected for payment using a random draw from a bingo cage. Experimental francs were used throughout the experiment, 
with a conversion rate of 25 francs $=\$ 1$. Participants earned $\$ 17$ on average, and sessions (including instruction time) lasted approximately 70 minutes.

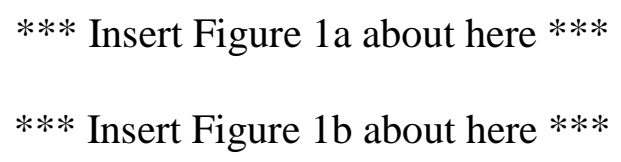

\section{Results}

Table 1 reports the average contributions and payoffs across both treatments, separately for each public goods dilemma. We find that in each treatment, participants make relatively similar contributions to both public goods on average. Figure 2 displays, by treatment, the average contribution (across both public goods dilemmas) over all 20 rounds of the experiment.

We find that contributions are 56.6\% higher when group composition is different across both public goods dilemmas as compared to when composition is the same across the two public goods dilemmas $\left(\mathrm{M}_{1}=17.7, \mathrm{SD}_{1}=13.2, \mathrm{n}_{1}=64\right.$ versus $\mathrm{M}_{2}=11.3, \mathrm{SD}_{2}=14.2, \mathrm{n}_{2}=40$; means reported in experimental 'francs'). Not only this result is practically significant (McCloskey \& Ziliak, 1996), but it is also statistically different. Comparing the two treatments using a twosample t-test finds these means to be statistically different at the $5 \%$ level, $p=0.02 .{ }^{1}$ The same statistical conclusion is supported even when using a conservative non-parametric test that treats each group of participants as one independent observation $\left(\mathrm{M}_{1}=17.7, \mathrm{SD}_{1}=4.4, \mathrm{n}_{1}=4\right.$ versus $\mathrm{M}_{2}=11.3, \mathrm{SD}_{2}=12.8, \mathrm{n}_{2}=10 ;$ Wilcoxon rank-sum test, $\left.\mathrm{p}=0.05\right){ }^{2}$

The results above provide evidence in support of Hypothesis 2, suggesting that individuals contribute more toward multiple public goods when involved in different groups as compared to when involved in the same groups. However, these results do not refute the existence of divided loyalists, but simply provide evidence for the existence of conditional 
cooperators. Indeed, it may be the case that divided loyalists exist alongside conditional cooperators; but in our experiment conditional cooperators are observed significantly more than divided loyalists and thus we find support for Hypothesis 2.

***Insert Table 1 and Figure 2 about here $* * *$

\section{Identifying Cooperators}

Hypothesis 2 suggests conditional cooperation as an explanation for the difference in cooperation between the Same treatment and the Different treatment. In the below, we define cooperators as participants who contribute more than $75 \%$ of their endowment. These are the individuals who either have an intrinsic motivation to be more cooperative, or cooperate based on observing other cooperators in earlier rounds. Table 2 reports the distribution of cooperators as a percentage of the total number of individuals. Comparing the two treatments, we find that in the first round of the experiment there are more cooperators $(18.8 \%$ more $)$ in the Same treatment than in the Different treatment, but the difference is not statistically different $\left(\mathrm{M}_{1}=0.203, \mathrm{SD}_{1}=\right.$ $0.051, \mathrm{n}_{1}=64$ versus $\mathrm{M}_{2}=0.250, \mathrm{SD}_{2}=0.069, \mathrm{n}_{2}=40 ; \mathrm{t}$-test, $\left.\mathrm{p}=0.71\right)$. However, in the last 10 rounds of the experiment, there are twice as many cooperators left in the Different treatment than in the Same treatment, and the difference is statistically different at the $10 \%$ level $\left(\mathrm{M}_{1}=0.059\right.$, $\mathrm{SD}_{1}=0.017, \mathrm{n}_{1}=64$ versus $\mathrm{M}_{2}=0.025, \mathrm{SD}_{2}=0.009, \mathrm{n}_{2}=40 ; \mathrm{t}$-test, $\left.\mathrm{p}=0.07\right)$. This observation provides additional support for Hypothesis 2, suggesting that participants who interact with two different groups of individuals may learn how to maintain cooperation better than participants who interact with only one group of individuals.

*** Insert Table 2 about here *** 
How do participants maintain better cooperation in the Different treatment as compared to the Same treatment? Table 3 displays the average contribution in round $t$ conditional on group contribution in round $t-1$. When examining the Different treatment, we find that if group contribution in round $t-1$ to the first public good is greater than group contribution to the second public good, participants choose to contribute $121 \%$ more in round $t$ to the first public good. If the group contribution in round $t-1$ to the second public good is greater than the group contribution to the first public good, participants choose to contribute $171 \%$ more in round $t$ to the second public good. These findings suggest that participants in the Different treatment shift their contributions to the public goods dilemmas with higher cooperation rates - thereby acting as conditional cooperators between games.

When examining the Same treatment, we find a similar type of behavior; however, the magnitude of shifts is much lower. If group contribution in round $t-1$ to the first public good is greater than group contribution to the second public good, participants choose to contribute $40 \%$ more in round $t$ to the first public good than to the second public good (12.8 vs. 9.1). Similarly, if the group contribution in round $t-1$ to the second public good is more than the group contribution to the first public good, participants choose to contribute $76 \%$ more in round $t$ to the second public good than to the first public good (11.3 vs. 6.4). The finding that participants in the Different treatment shift their contributions much more than participants in the Same treatment is statistically different at the 5\% level and can help explain the difference in overall cooperation rates between treatments (t-test, both p's $<0.05$; Wilcoxon rank-sum test, both p's $<0.05$ ). ${ }^{3}$

Additional evidence of greater shifting of contributions in the Different treatment relative to the Same treatment comes from comparing the number of instances when participants choose to contribute more than half of their endowment to one of the public goods dilemmas. 
Specifically, we find that in the Different treatment, participants transfer more than half of their endowment to one of the two public goods dilemmas $5.5 \%$ of the time. On the other hand, in the Same treatment the transfer rate is less than half or $2.3 \%$ of instances. The difference in these transfer rates are statistically different at the 5\% level for the individual level analysis and 10\% level at the group level of analysis (t-test, $\mathrm{p}=0.04, \mathrm{n}_{1}=64, \mathrm{n}_{2}=40$; Wilcoxon rank-sum test, $\mathrm{p}=$ $0.10, \mathrm{n}_{1}=4, \mathrm{n}_{2}=10$ ). Note that the number of participants who transfer more than half may be low overall because participants tend to keep a large portion of their endowment rather than give it to the public good. Our findings comport with the results of Falk and colleagues (2013) where it was found that individuals participating in public goods dilemmas with different group members and found evidence for social interactions: individuals contribute more to groups in which others are also contributing.

\footnotetext{
*** Insert Table 3 about here ***
}

\section{Analyzing the Determinants of Contributions}

Table 4 reports estimates of panel regressions conducted separately for each public goods dilemma. In these regressions, the dependent variable is participant's contribution to the first public good (regression models 1 and 3) and to the second public good (regression models 2 and 4). The independent variables are contribution-1-lag (lagged individual contribution to the first public good), contribution-2-lag (lagged individual contribution to the second public good), group-contribution-1-lag (lagged group contribution to the first public good), and groupcontribution-2-lag (lagged group contribution to the second public good). All regressions use a random effects error structure for the individual participants to account for repeated measures, a period trend to account for learning, and include a constant. Standard errors are clustered at the matching group level. 
In the Same treatment, according to the estimation results in regression (model 1), the main determinants of contribution in the first public good are contribution-1-lag and groupcontribution-1-lag, indicating that the two major factors influencing contributions are an individual disposition towards cooperation (i.e., tendency of a participant to contribute continually to the public good) and social interaction (i.e., contributing to the first public good conditional on group cooperation level). Similar results are reported in regression (model 2) for the second public good of the Same treatment.

In the Different treatment, the determinants of contribution are more complex. According to the estimation results in regression (model 3), the determinants of contribution in the first public good are contribution-1-lag contribution-2-lag, suggesting strong individual disposition effects. Further, the contribution in the first public good is positively correlated with groupcontribution-1-lag and negatively correlated with group-contribution-2-lag. The positive correlation suggests that in the Different treatment, conditional cooperators are more responsive to the behavior of the two groups. Conditional cooperators contribute more to the first public good if they observe cooperative behavior in the first public good in the previous round, but they contribute less to the first public good if they observe more cooperative behavior in the second public good in the previous round. This is also true when we examine regression (model 4) for the second public good. Overall, these findings reveal a mechanism used by individuals to achieve higher cooperation in the Different treatment than in the Same treatment: participants in the Different treatment conditionally shift their contributions from a less cooperative group to a more cooperative group (there is no such evidence in the Same treatment).

*** Insert Table 4 about here $* * *$ 


\section{Discussion and Conclusion}

We experimentally investigated simultaneous decision-making in two public goods dilemmas with different and same group members. In our two treatments, participants were limited by a single budget constraint and chose how to allocate their endowment across two public goods and a private account. We found that the choice of contribution when facing multiple social dilemmas with different groups led to greater overall cooperation (56.6\% more) compared to same groups. The difference in cooperation is because conditional cooperators were able to band together. This finding supports the conditional-cooperator hypothesis (from the behavioral economics literature) compared to the divided-loyalist hypothesis (from the organizational theory literature). Although participants have inherent individual disposition towards cooperation (i.e., their contributions are correlated across different rounds of the experiment), they are also conditionally cooperative (i.e., their contributions are correlated with their group contributions across different rounds of the experiment). Moreover, we find that over the course of the experiment, participants playing with different group members shift their contributions significantly more (about 4 times more) towards more cooperative groups than participants playing with the same group members. ${ }^{4}$

\section{Implications and Future Research Directions}

Messick and Brewer's (1983) seminal paper outlines several guidelines for assessing a study's contributions to the social dilemma literature. The first guideline is about advancing our understanding about a common type of social dilemma. The second guideline involves contributing to scholarly conversation outside the social dilemma domain. Messick and Brewer's third criterion concerns the practical significance of a study's finding in relation to public policy 
and management. Following these guidelines, our findings push our thinking about social dilemmas and social cooperation in several ways.

Implications for social dilemma research. We introduce an alternative form of discretion into the conversation of social dilemmas in organizations. Discretion refers to the "latitude of actions available to a [decision maker]" (Finkelstein \& Hambrick, 1990, p. 484). When we talk about discretion in social dilemmas, we are often referring to discretion about whether or not to cooperate, defect, or sanction defectors (e.g., De Cremer \& van Dijk, 2009; Polzer et al., 1999). Our study introduces a different form of discretion: discretion over which collective action to undertake. Of course, individuals can always decide whether to assist or impede collective action, but our study observes that individuals can also decide which collective action to assist and which to impede. Examining this different source of discretion in the conversation of social dilemmas enhances the paradigm's ecological validity and leaves room for answering the transparadigmatic question, what can collectives do to look attractive to conditional cooperators?

In our study, the attractiveness of a social dilemma was constituted by how many cooperators were present. However, as observed by Weber et al. (2004), when a person faces a social dilemma, the person not only considers the incentives but also subconsciously asks and answers the question "What does a person like me do in a social dilemma like this?" In other words, decisions are made on "logics of appropriateness" in addition to logics of consequences (Messick, 1999). The idea of the logic of appropriateness is that individuals make their decisions based on the perceived context of the situation, that individual's role in the situation, and the rules appropriate to that situation (March, 1994).

In relation to appropriateness logic, we know that whether a social dilemma is framed as a business decision or moral decision impacts an individual's cooperation tendencies 
(Tenbrunsel \& Messick, 1999). We also know that cooperation changes as a function of an individual role as a leader or a follower in social dilemmas (De Cremer, 2003). Indeed, recent scholarship reminds us that relative wealth is a cue that affects whether an individual deems it appropriate to be cooperative or not (McCarter, Budescu, \& Scheffran, 2011). Using the logic of appropriateness, future scholarship may address the questions "How decision frames impact a person's choice of being a divided loyalist or a consistent cooperator?", "What cues from the situation affect how a person perceives their role in the social dilemma?", and "How does this role perception moderate the framing effect?" It could be that framing multiple simultaneous social dilemmas as moral decisions increase cooperation across dilemmas but this increase is moderated by the wealth the players have in relation to each other.

In relation to the management research domain of cooperation, our paper patterns after recent advancements placing greater focus on the processes individuals - be they people or firms - use to manage cooperation dilemmas in organizations. Whereas previous research examines how process, as well as structural, elements affect satisfaction with partners when cooperating (Lui \& Ngo, 2005) the current paper examines how changes in group structure (same versus different groups) affect the cooperation processes individuals use to achieve collective action. Considering previous work examining how communication processes (with words) affect cooperation behavior in organizational social dilemmas (Young-Ybarra \& Wiersema, 1999), future research may profit from examining whether cooperation processes of behavior speak louder than cooperation processes of words.

Implications for social cooperation research. In a broader sense, our paper shifts the discussion about social cooperation from the well-studied Hardinic approach to the lessexamined Simonic approach. The Hardinic approach - named after Garrett Hardin (1968) - 
predicts that, without coercion from a central authority, individuals will rarely achieve collective action because of greed and fear of exploitation. In other words, the Hardinic approach maintains that without coercion, organizational systems become pejoristic systems or systems that perform worse over time (Hardin, 1974). The divided-loyalist hypothesis is a Hardinic hypothesis: it predicts that an individual will think the worst of (other individuals in) the situation and, consequentially, will not cooperate to produce public goods (McCarter \& Northcraft, 2007).

In contrast to Hardin's approach, the Simonic approach - named after Julian Simon (1996) - suggests that, given the right institution or market structure, individuals will find creative ways (without coercion) to change their circumstances, achieve collective action, and consequently enhance social welfare. In other words, the Simonic approach maintains that, given the opportunity (and without coercion), individuals will make an organizational system into a melioristic one, where the system performs better over time. The conditional-cooperator hypothesis is a Simonic one. The conditional-cooperator hypothesis is about individuals looking for the best in the situation - i.e., they will seek out and find cooperators just like themselves and find a way to achieve collective action.

Our findings provide preliminary support for Simon's position in the conversation of social cooperation. It seems that organizational systems attempting collective action can perform better when individuals are given the discretion of who to work with when creating value. Considering that Simon's work is only mentioned in a handful of social dilemma articles and book chapters (i.e., Gifford, 2008a, 2008b, 2011; Koger \& Winter, 2010), future social dilemma research may benefit from examining how Simon and Hardin's views complement one another. ${ }^{5}$

Implications for policy. Our last contribution is a "sizable" one for policy makers and managers. From sociology (Gold, 1969) to psychology (Kirk, 1996), and from economics 
(McCloskey \& Ziliak, 1996) to management (Orlitzky, 2012), scholarship suggests that assessing the size of an effect is just as critical as assessing whether there is an effect. We find not only the difference between the treatments is different statistically at the conventional level, but it is practically significant - the difference in cooperation between the two treatments is $56.6 \%$. Should these findings hold in magnitude to other contexts, our findings provide insights about institutional design. For instance, an administrator faced with a task of assigning individuals to work teams may increase economic welfare by assigning individuals to work with different, rather than same, team members. Future work would benefit from replicating our results in different contexts and populations to enhance their generalizability.

One of the current paper's authors recently saw a bumper sticker that read "If you don't like it here, then move!" Indeed, in studying how cooperation develops in multiple simultaneous social dilemmas, we found that people follow the bumper sticker's advice. People vote with their feet when it comes to attempting collective action. In support of the conditional-cooperator hypothesis applied to public goods dilemmas, those wishing to enhance social welfare find another place to go and in so doing find others with the same wish of achieving collective action. 


\section{Statistical Analysis Addendum}

STATA/IC version 12 was used throughout the paper to conduct our analyses. All t-tests use command ttest and non-parametric t-tests use command ranksum (the Wilcoxon MannWhitney test). Random effect regression models used command $x$ treg with $c l$ option for clustering. All data are available from the authors upon request.

\section{Funding}

This research was made possible by a grant from the International Foundation of Research in Experimental Economics (IFREE) awarded to the second author.

\section{Declaration of Conflicting Interests}

The authors declare no potential conflicts of interest with respect to the authorship, research, and/or the publication of this article.

\section{Authors' Note}

We thank editors Bill Gardner and Gayle Baugh, associate editor Hongwei He, and two anonymous reviewers for their guidance and comments on earlier drafts of this manuscript. 


\section{Endnotes}

${ }^{1}$ In conducting this t-test, we used the average contribution per participant across both public goods dilemmas and over all 20 periods of play as one observation.

${ }^{2}$ In the Same treatment one independent observation is a group of 4 participants (40 participants $=10$ groups $=10$ independent observations), while in the Different treatment one independent observation is one session (64 participants $=4$ sessions $=4$ independent observations).

${ }^{3}$ We constructed 10 independent observations in the Same treatment (40 participants = 10 groups $=10$ independent observations) and 4 observations in the Different treatment (64 participants $=4$ sessions $=4$ independent observations). Each observation was the average difference between the contribution to the first public good (second public good) and second public good (first public good), conditional on higher group contribution to the first public good (second public good) in the previous round.

${ }^{4}$ Existence of conditional cooperators, however, does not refute existence of divided loyalists. Indeed, it may be the case that divided loyalists exist alongside conditional cooperators. But, in our experiment conditional cooperators significantly outperform divided loyalists, and thus we find support for Hypothesis 2.

${ }^{5}$ Indeed, the Hardinic approach is more popular than the Simonic approach. A search on Google Scholar (February 27, 2014) comparing the frequency of papers about "social cooperation" or "social decision making", that cite Hardin's (1968) seminal article The tragedy of the commons to Simon's (1996) seminal book The ultimate resource 2, finds the number of papers to be 559 for Hardin and 35 for Simon. Another search on Google Scholar (February 27, 2014) comparing the frequency of papers discussing a "social dilemma" finds that cite Hardin to Simon finds the number of papers to be 1,470 for Hardin and 7 for Simon. The asymmetric pattern holds when we control for the total number of citations for each work: $2.4 \%(559 / 23,194)$ versus $1.6 \%(35 / 2,204)$ for the "social cooperation / social decision making" search and 6.3\% $(1,470 / 23,194)$ versus $.03 \%(7 / 2,204)$ for the "social dilemma" search. 


\section{References}

Aquino, K., \& Reed, A. (1998). A social dilemma perspective on cooperative behavior in organizations. Group and Organization Management, 23(4), 390-413.

Bednar, J., Chen, Y., Liu, T. X., \& Page, S. (2012). Behavioral spillovers and cognitive load in multiple games: An experimental study. Games and Economic Behavior, 74(1), 12-31.

Berkowitz, L., \& Donnerstein, E. (1982). External validity is more than skin deep: Some answers to criticisms of experiments. American Psychologist, 37(3), 245-257.

Bernasconi, M., Corazzini, L., Kube, S., \& Marechal, M. (2009). Two are better than one! Individuals' contributions to "unpacked" public goods. Economic Letters, 104(1), 31-33.

Biele, G., Rieskamp, J., \& Czienskowski, U. (2009). Explaining cooperation in groups: Testing models of reciprocity and learning. Organizational Behavior and Human Decision Processes, 106(2), 89-105.

Cason, T. N., Savikhin, A. C., \& Sheremeta, R. M. (2012). Behavioral spillovers in coordination games. European Economic Review, 56(2), 233-245.

Cassar, A., \& Friedman, D. (2004). Economics lab: An intensive course in experimental economics. New York, NY: Routledge.

Cook, T. D., \& Campbell, D. T. (1979). Quasi-experimentation: Design and analysis issues for field settings. Boston, MA: Houghton Mifflin Company.

Creswell, J. W. (2008). Research design: Qualitative, quantitative, and mixed methods approaches. Thousand Oaks, CA: Sage.

Cross, J. G., \& Guyer, M. J. (1980). Social traps. Ann Arbor, MI: University of Michigan Press.

Dawes, R. M. (1980). Social dilemmas. Annual Review of Psychology, 31, 169-193.

De Cremer, D. (2003). How self-conception may lead to inequality: Effect of hierarchical roles on the equality rule in organizational resource-sharing tasks. Group and Organization Management, 28(2), 282-302.

De Cremer, D., \& van Dijk, E. (2009). Paying for sanctions in social dilemmas: The effects of endowment asymmetry and accountability. Organizational Behavior and Human Decision Processes, 109(1), 45-55.

Deutsch, M., \& Gerard, H. B. (1955). A study of normative and informational social influences upon individual judgment. Journal of Abnormal and Social Psychology, 51(3), 629-636.

Falk, A., Fischbacher, U., \& Gächter, S. (2013). Living in two neighborhoods: Social interaction effects in the laboratory. Economic Inquiry, 51(1), 563-578. 
Ferrin, D. L., Bligh, M. C., \& Kohles, J. C. (2007). Can I trust you to trust me?: A theory of trust, monitoring, and cooperation in interpersonal and intergroup relationships. Group and Organization Management, 32(4), 465-499.

Finkelstein, S., \& Hambrick, D. C. (1990). Top-management-team tenure and organizational outcomes: The moderating role of managerial discretion. Administrative Science Quarterly, 35(3), 484-503.

Fischbacher, U. (2007). z-Tree: Zurich toolbox for ready-made economic experiments. Experimental Economics, 10(2), 171-178.

Fischbacher, U., Gächter, S., \& Fehr, E. (2001). Are people conditionally cooperative? Evidence from a public goods experiment. Economic Letters, 71(3), 397-404.

Friedman, D., \& Sunder, S. (1994). Experimental methods: A primer for economists: Cambridge University Press.

Gächter, S. (2007). Conditional cooperation: Behavioral regularities from the lab and the field and their policy implications. In B. S. Frey \& A. Stutzer (Eds.), Economics and psychology: A promising new cross-disciplinary field). Cambridge, MA: MIT Press.

Gifford, R. (2008a). Psychology's essential role in alleviating the impacts of climate change. Canadian Psychology/Psychologie Canadienne, 49(4), 273-280.

Gifford, R. (2008b). Toward a comprehensive model of social dilemmas. In A. Biel, D. Eek, T. Garling \& M. Gustafson (Eds.), New issues and paradigms in research on social dilemmas (pp. 265-279). New York, NY: Springer.

Gifford, R. (2011). The dragons of inaction: Psychological barriers that limit climate change mitigation and adaptation. American Psychologist, 66(4), 290-302.

Gold, D. (1969). Statistical tests and substantive significance. American Sociologist, 4(1), 42-46.

Greiner, B. (2004). The Online Recruitment System ORSEE 2.0 - A guide for the organization of experiments in economics, Working Paper Series in Economics \#10). University of Cologne.

Hardin, G. (1968). The tragedy of the commons. Science, 162(3859), 1243-1248.

Hardin, G. (1974). Living on a lifeboat. BioScience, 24(10), 561-568.

Hollenbeck, J. R. (2008). The role of editing in knowledge development: Consensus shifting and consensus creation. In Y. Baruch, A. M. Konrad, H. Aguinus \& W. H. Starbuck (Eds.), Journal editing: Opening the black box (pp. 16-26). San Francisco, CA: Jossey Bass.

Ichino, A., \& Maggi, G. (2000). Work environment and individual background: Explaining regional shirking differentials in a large Italian firm. Quarterly Journal of Economics, 115(3), 1057-1090. 
Janssen, M. A., \& Ostrom, E. (2006). Governing social-ecological systems. In L. Tesfatsion \& K. L. Judd (Eds.), Handbook of computational economics (pp. 1465-1509). Oxford, UK: Elsevier.

Kirk, R., E. (1996). Practical significance: A concept whose time has come. Educational \& Psychological Measurement, 56(5), 746-759.

Koger, S. M., \& Winter, D. D. (2010). What on Earth are we doing? In S. M. Koger \& D. D. Winter (Eds.), The psychology of environmental problems: Psychology for sustainability (pp. 129). New York, NY: Psychology Press.

Kollock, P. (1998). Social dilemmas: The anatomy of cooperation. Annual Review of Sociology, 24, 183-214.

Lui, S. S., \& Ngo, H.-Y. (2005). An action pattern model of inter-firm cooperation. Journal of Management Studies, 42(6), 1123-1153.

March, J. G. (1994). A primer of decision making: How decisions happen. New York, NY: Free Press.

McCarter, M. W., Budescu, D. V., \& Scheffran, J. (2011). The give-or-take-some dilemma: An empirical investigation of a hybrid social dilemma. Organizational Behavior and Human Decision Processes, 116(1), 83-95.

McCarter, M. W., \& Northcraft, G. B. (2007). Happy together? Insights and implications of viewing managed supply chains as a social dilemma. Journal of Operations Management, 25(2), 498-511.

McCarter, M. W., Rockmann, K. W., \& Northcraft, G. B. (2010). Is it even worth it? The effect of loss prospects in the outcome distribution of a public goods dilemma. Organizational Behavior and Human Decision Processes, 111(1), 1-11.

McCarter, M. W., \& Sheremeta, R. M. (2013). You can't place old wine in new bottles: The effect of newcomers on coordination in groups. PLoS ONE, 8(1), e55058.

McCloskey, D. N., \& Ziliak, S. T. (1996). The standard error of regressions. Journal of Economic Literature, 34(1), 97-114.

Messick, D. M. (1999). Alternative logics for decision making in social settings. Journal of Economic Behavior and Organization, 39(1), 11-28.

Messick, D. M., \& Brewer, M. (1983). Solving social dilemmas. In L. Wheeler, \& Shaver, P. (Ed.), Review of personality and social psychology (pp. 11-44). Beverly Hills: Sage Publications.

O’Leary, M. B., Woolley, A. W., \& Mortensen, M. (2011). Multiteam membership in relation to multiteam systems. In S. Zaccaro, M. Marks \& L. DeChurch (Eds.), Multi-team systems: An organization form for dynamic and complex environments (pp. 141-172). New York, NY: Taylor $\&$ Francis. 
Olson, M. (1965). The logic of collective action: Public goods and the theory of groups. Cambridge, MA: Harvard University Press.

Orlitzky, M. (2012). How can significance tests be deinstitutionalized? Organizational Research Methods, 15(2), 199-228.

Polzer, J. T., Stewart, K. J., \& Simmons, J. L. (1999). A social categorization explanation for framing effects in nested social dilemmas. Organizational Behavior and Human Decision Processes, 79(2), 154-178.

Rockmann, K. W., \& Northcraft, G. B. (2008). To be or not to be trusted: The influence of media richness on defection and deception. Organizational Behavior and Human Decision Processes, 107(2), 106-122.

Samuelson, P. A. (1954). The pure theory of public expenditure. Review of Economic and Statistics, 36(4), 387-389.

Sandberg, J., \& Alvesson, M. (2011). Ways of constructing research questions: gap-spotting or problematization? Organization, 18(1), 23-44.

Savikhin, A. C., \& Sheremeta, R. M. (2013). Simultaneous decision-making in competitive and cooperative environments. Economic Inquiry, 51(2), 1311-1323.

Simon, J. M. (1996). The ultimate resource 2. Princeton, N.J.: Princeton University Press.

Tenbrunsel, A. E., \& Messick, D. M. (1999). Sanctioning systems, decision frames, and cooperation. Administrative Science Quarterly, 44(4), 684-707.

Thorngate, W. (1976). Possible limits on a science of social behavior. In L. H. Strickland, F. E. Aboud \& K. J. Gergen (Eds.), Social psychology in transition (pp. 121-139). New York, NY: Springer.

Van Lange, P. A. M., Joireman, J., Parks, C. D., \& Van Dijk, E. (2013). The psychology of social dilemmas: A review. Organizational Behavior and Human Decision Processes, 120(2), 125-141.

Weber, J. M., Kopelman, S., \& Messick, D. M. (2004). A conceptual review of decision making in social dilemmas: Applying a logic of appropriateness. Personality and Social Psychology Review, 8(3), 281-307.

Wit, A. P., \& Kerr, N. L. (2002). "Me versus just us verus all” categorization and cooperation in nested social dilemmas. Journal of Personality and Social Psychology, 83(3), 616-637.

Yamagishi, T., \& Sato, K. (1986). Motivational bases of the public goods dilemma. Journal of Personality and Social Psychology, 50(1), 67-73. 
Young-Ybarra, C., \& Wiersema, M. (1999). Strategic flexibility in information technology alliances: The influence of transaction cost economics and social exchange theory. Organization Science, 10(4), 439-459.

Zeng, M., \& Chen, X.-P. (2003). Achieving cooperation in multiparty alliances: A social dilemma approach to partnership management. Academy of Management Review, 28(4), 587605 . 
Table 1: Contribution to public goods is higher in the Different treatment than in the Same treatment

\begin{tabular}{llcc}
\hline \hline Treatment & & Contribution & Payoff \\
\hline \multirow{4}{*}{ Same } & Same-1 & $11.8(17.4)$ & $7.1(12.0)$ \\
& Same-2 & $10.8(13.0)$ & $6.5(10.4)$ \\
\cline { 2 - 4 } Different & Average & $\mathbf{1 1 . 3 ( 1 4 . 2 )}$ & $\mathbf{6 . 8 ( 1 0 . 3 )}$ \\
\hline \multirow{3}{*}{} & Different-1 & $16.4(15.2)$ & $9.8(12.3)$ \\
& Different-2 & $19.1(17.1)$ & $11.4(13.6)$ \\
\cline { 2 - 4 } & Average & $\mathbf{1 7 . 7 ( 1 3 . 2 )}$ & $\mathbf{1 0 . 6 ( 1 0 . 2 )}$ \\
\hline
\end{tabular}

Note: Standard deviation in parentheses. Means reported in experimental francs. Key comparison bolded. 
Table 2: There are twice as many cooperators in the Different treatment than in the Same treatment in the last 10 rounds of the experiment

\begin{tabular}{lcc}
\hline \hline Treatment & Round & Cooperators \\
\hline \multirow{3}{*}{ Same } & 1 & $25.0 \%$ \\
& $2-10$ & $8.3 \%$ \\
& $11-20$ & $\mathbf{2 . 5 \%}$ \\
\hline \multirow{3}{*}{ Different } & 1 & $20.3 \%$ \\
& $2-10$ & $8.5 \%$ \\
& $11-20$ & $\mathbf{5 . 9 \%}$ \\
\hline
\end{tabular}

Key comparison bolded. 
Table 3: The percentage shift of contribution towards more cooperative group in the Different treatment is much higher than in the Same treatment

\begin{tabular}{llccc}
\hline \hline Treatment & & $\begin{array}{c}\text { Group Contribution } \\
\text { in Round } t \text {-1 }\end{array}$ & $\begin{array}{c}\text { Contribution } \\
\text { in Round } t\end{array}$ & $\begin{array}{c}\text { Percentage Shift of } \\
\text { Contribution }\end{array}$ \\
\hline \multirow{4}{*}{ Same } & Same-1 & Same-1 $\geq$ Same-2 & $12.8(26.2)$ & $\mathbf{4 0 \%}$ \\
& Same-2 & Same-1 $\geq$ Same-2 & $9.1(20.6)$ & \\
& Same-1 & Same-1 $<$ Same-2 & $6.4(14.5)$ & \\
& Same-2 & Same-1 $<$ Same-2 & $11.3(19.5)$ & $\mathbf{7 6 \%}$ \\
\hline \multirow{4}{*}{ Different } & Different-1 & Different-1 $\geq$ Different-2 & $19.7(32.6)$ & $\mathbf{1 2 1 \%}$ \\
& Different-2 & Different-1 $\geq$ Different-2 & $8.9(18.4)$ & \\
& Different-1 & Different-1 < Different-2 & $10.7(19.1)$ & \\
& Different-2 & Different-1 $<$ Different-2 & $29.0(30.0)$ & $\mathbf{1 7 1 \%}$ \\
\hline
\end{tabular}

Standard deviation in parentheses. The percentage shift of contribution towards more cooperative group in the Different treatment (121\% and 171\%) is much higher than in the Same treatment (40\% and $76 \%)$. Key comparison bolded. 


\section{Table 4: Random effect models of individual contributions}

\begin{tabular}{|c|c|c|c|c|}
\hline \multirow{2}{*}{$\begin{array}{l}\text { Treatment } \\
\text { Individual }\end{array}$} & \multicolumn{2}{|c|}{ Same } & \multicolumn{2}{|c|}{ Different } \\
\hline & (1) & (2) & (3) & (4) \\
\hline Contribution in & Same-1 & Same-2 & Different-1 & Different-2 \\
\hline \multirow[t]{2}{*}{ contribution-1-lag } & $0.29 * *$ & 0.11 & $0.27 * * *$ & $0.08^{*}$ \\
\hline & $(0.14)$ & $(0.13)$ & $(0.03)$ & $(0.04)$ \\
\hline \multirow[t]{2}{*}{ contribution-2-lag } & 0.04 & $0.30 * * *$ & $0.07 * *$ & $0.47 * * *$ \\
\hline & $(0.08)$ & $(0.08)$ & $(0.03)$ & $(0.02)$ \\
\hline \multirow[t]{2}{*}{ group- contribution-1-lag } & $0.13 * * *$ & 0.01 & $0.12 * * *$ & $-0.04 * * *$ \\
\hline & $(0.02)$ & $(0.02)$ & $(0.01)$ & $(0.00)$ \\
\hline \multirow[t]{2}{*}{ group- contribution -2-lag } & 0.01 & $0.08 * * *$ & $-0.01 * *$ & $0.09 * * *$ \\
\hline & $(0.03)$ & $(0.03)$ & $(0.01)$ & $(0.00)$ \\
\hline \multirow[t]{2}{*}{ round } & -9.01 & -0.09 & -5.76 & 9.58 \\
\hline & $(6.50)$ & $(5.45)$ & (5.99) & $(6.42)$ \\
\hline \multirow[t]{2}{*}{ constant } & 1.38 & 1.26 & $3.16^{* * *}$ & $1.84 * *$ \\
\hline & $(0.86)$ & $(1.20)$ & $(1.01)$ & $(0.80)$ \\
\hline Observations & 760 & 760 & 1216 & 1216 \\
\hline Number of clusters & 10 & 10 & 4 & 4 \\
\hline Overall $R$-squared & 0.49 & 0.36 & 0.29 & 0.47 \\
\hline
\end{tabular}


Figure 1a: Decision-making screen for the Different treatment

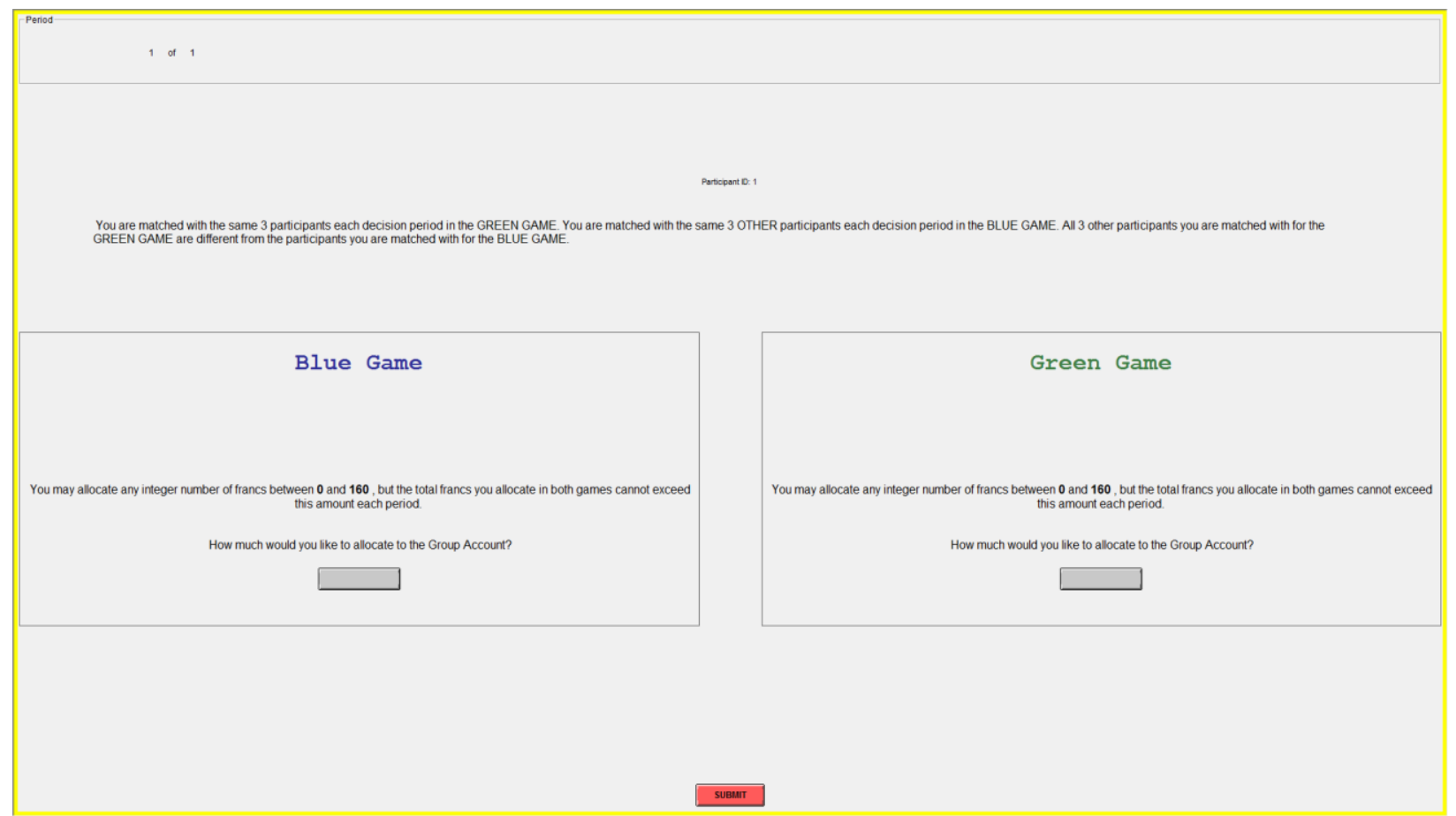


Figure 1b: Decision-making screen for the Same treatment

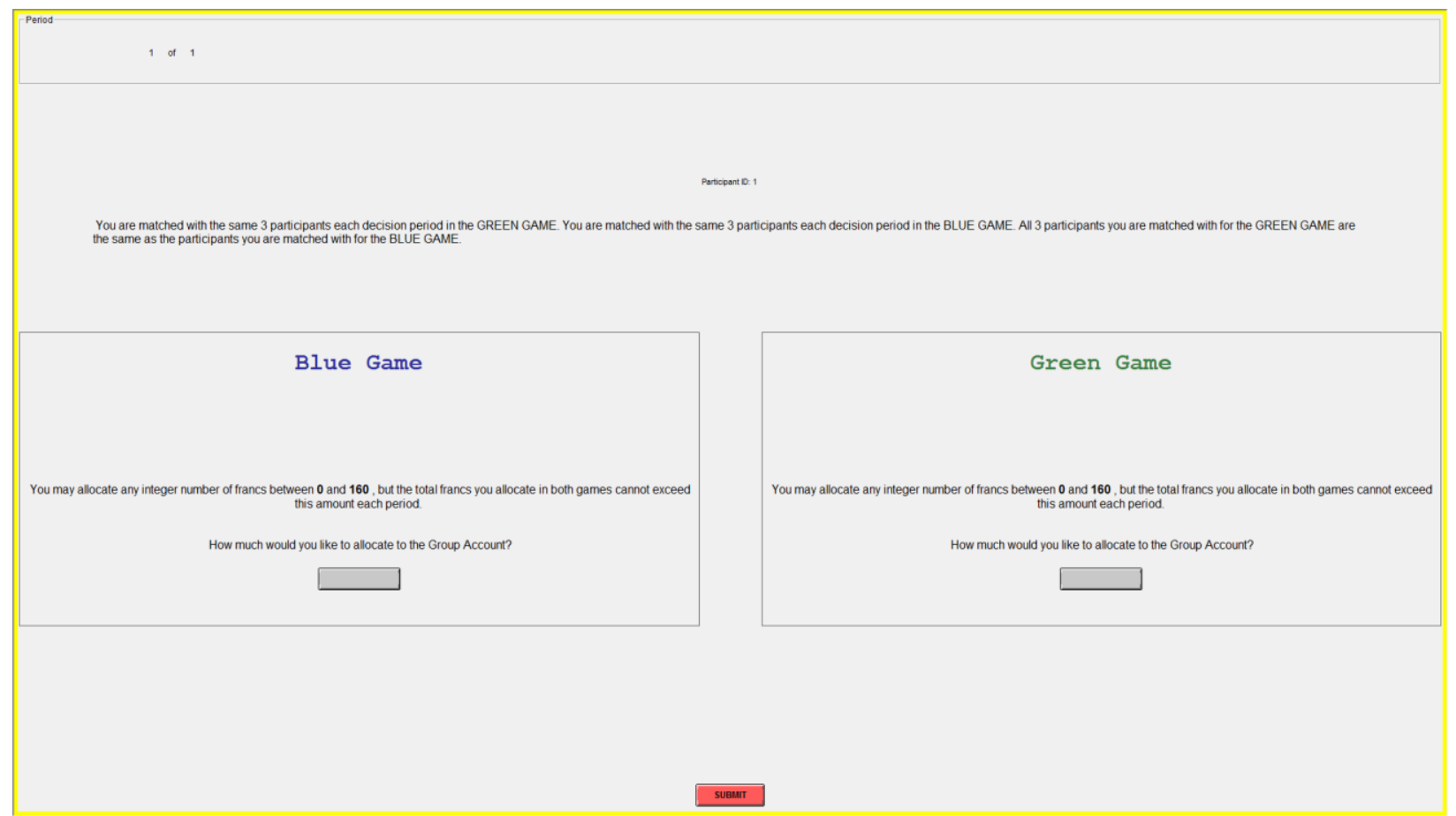


Figure 2: The average contribution across rounds is greater for the Different Condition than the Same Condition

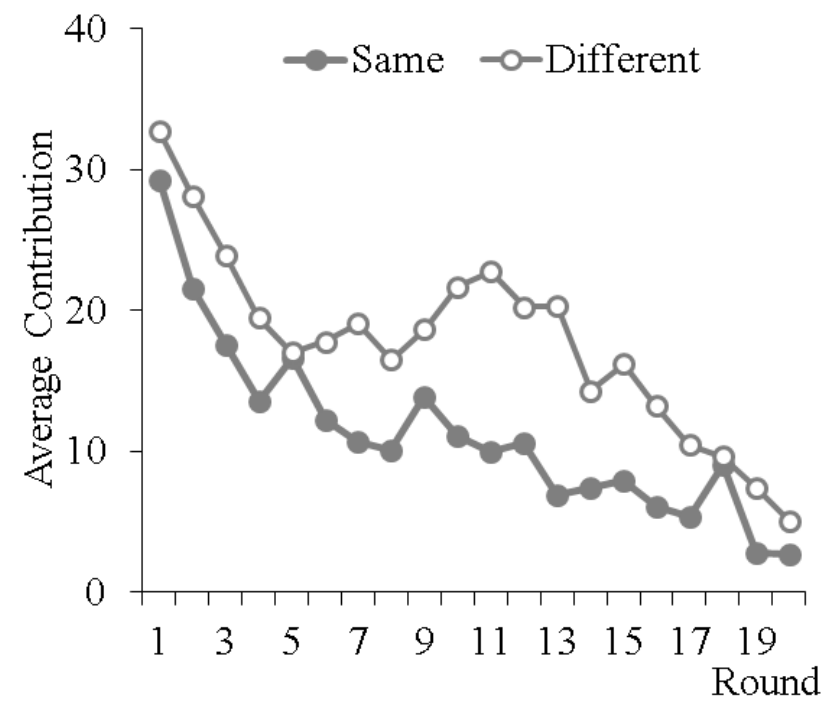




\section{Appendix}

\section{Instructions for the Same Treatment}

In this experiment you will participate in two games. Each of the two games will have four participants, including you. You will not know the identity of the participants you are grouped with. The experiment will consist of 20 periods. You will participate in a BLUE GAME and a GREEN GAME at the same time. BLUE GAME and GREEN GAME have exactly the same rules. You will participate in the BLUE GAME with the same three participants. You will participate in the GREEN GAME with the same three participants. All three other participants you are matched with for the GREEN GAME are the same as the participants you are matched with for the BLUE GAME. The BLUE GAME will appear on the left side of the screen and the GREEN GAME will appear on the right side of the screen at the same time in all 20 periods.

At the end of the experiment $\mathbf{2}$ out of $\mathbf{2 0}$ periods will be randomly selected for payment. After you have completed all periods two tokens will be randomly drawn out of a bingo cage containing tokens numbered from 1 to 20. The token numbers determine which two periods are going to be paid.

Each period you will be given 160 francs. Francs will be converted to U.S. dollars at the end of the experiment at the rate of $\mathbf{2 5}$ francs $=\mathbf{\$ 1}$. Each period, you will select an allocation for BLUE GAME and an allocation for GREEN GAME. When you are ready to make your decision, click on the "input boxes" below "How much would you like to allocate to Group Account in BLUE GAME?" and "How much would you like to allocate to Group Account in GREEN GAME?" and the program will allow you to enter in your number choices. When you are finished making your choices, click "Submit". You can allocate as much or as little of your francs as you like in each period, but remember that the total francs you choose to allocate must not exceed 160 francs in each period. You keep any francs which you do not allocate; therefore, your earnings are the sum of the francs you decided to keep, your earnings from BLUE GAME, and your earnings from GREEN GAME.

\section{BLUE (GREEN) GAME}

Below, we will read instructions for the BLUE GAME. However, the rules for the BLUE GAME and the GREEN GAME are exactly the same.

Each period you will decide how much of your endowment you want to allocate to a Group Account. You may allocate any integer number of francs between $\mathbf{0}$ and 160, as long as the total number of francs used for allocations in both games does not exceed 160. After all participants have made their decisions, your outcome for the period is calculated.

Your period outcome from BLUE GAME depends on the total number of francs allocated to the Group Account by all 4 group members (including you). In particular, your earnings from the Group Account are 40 percent of the total allocation of all 4 group members (including you) to the Group Account. Therefore, for every franc you allocate to the Group Account, you increase the total allocation to the Group Account by 1 franc. Therefore, your earnings from the Group Account rise by $0.4 \times 1=0.4$ francs. And the earnings of the other group members also rise by 0.4 francs each, so that the total earnings of the group from the Group Account rise by 1.6 francs.

In summary, your period outcome in BLUE GAME is determined as follows:

BLUE GAME Outcome $=$ (earnings from Group Account $)-($ your allocation to the Group Account $)=$ $=0.4 \times$ (allocation of 4 group members to Group Acct.) - (your allocation to Group Acct.)

Example: Suppose that you allocated 40 francs to the Group Account and that the other three members of your group allocated a total of 120 francs. This makes a total of 160 francs in the Group Account. In this case each member of the group receives earnings from the Group Account of $0.4 \times 160=$ 64 francs, which is also each member's period outcome in the BLUE GAME. 


\section{TOTAL EARNINGS}

After you choose how much to allocate to the Group Account in the BLUE GAME and how much to allocate to the Group Account in the GREEN GAME, the remainder of your 160 francs will be allocated to your Individual Account. Your earnings from the Individual Account equal to the francs that you keep for yourself and do not depend on the decisions of others. Therefore, for every franc you keep for yourself in your Individual Account, you earn 1 franc.

Your total earnings will be converted to cash and paid at the end of the experiment if the current period is the period that is randomly chosen for payment. Your total earnings for each period will be calculated as:

Total Earnings $=(160)+($ Outcome from BLUE GAME $)+($ Outcome from GREEN GAME $)=$
Which is the same as
$=160+($ Earnings from Group Account in BLUE GAME $)-($ allocation to Group Account in
BLUE GAME)
$+($ Earnings from Group Account in GREEN GAME)-(allocation to Group Account in GREEN
GAME)

OUTCOME SCREEN

At the end of each period, your allocation, the sum of all allocations in your group for each of BLUE GAME and GREEN GAME, and the outcome for each of BLUE GAME and GREEN GAME are reported on the outcome screen. The computer will also display your income from the individual account and your total earnings for the period. Once the outcome screen is displayed you should record your results for the period on your Personal Record Sheet under the appropriate heading.

At the end of the experiment $\mathbf{2}$ out of $\mathbf{2 0}$ periods will be randomly selected for payment. Your earnings for these two periods will be converted to U.S. dollars at the end of the experiment at the rate of 25 francs $=\$ 1$. 


\section{Instructions for the Different Treatment}

In this experiment you will participate in two games. Each of the two games will have four participants, including you. You will not know the identity of the participants you are grouped with. The experiment will consist of 20 periods. You will participate in a BLUE GAME and a GREEN GAME at the same time. BLUE GAME and GREEN GAME have exactly the same rules. You will participate in the BLUE GAME with the same three participants. You will participate in the GREEN GAME with the same three participants. However, all three other participants you are matched with for the GREEN GAME are different from the participants you are matched with for the BLUE GAME. The BLUE GAME will appear on the left side of the screen and the GREEN GAME will appear on the right side of the screen at the same time in all 20 periods.

At the end of the experiment $\mathbf{2}$ out of $\mathbf{2 0}$ periods will be randomly selected for payment. After you have completed all periods two tokens will be randomly drawn out of a bingo cage containing tokens numbered from 1 to 20. The token numbers determine which two periods are going to be paid.

Each period you will be given $\mathbf{1 6 0}$ francs. Francs will be converted to U.S. dollars at the end of the experiment at the rate of $\mathbf{2 5}$ francs $=\mathbf{\$ 1}$. Each period, you will select an allocation for BLUE GAME and an allocation for GREEN GAME. When you are ready to make your decision, click on the "input boxes" below "How much would you like to allocate to Group Account in BLUE GAME?" and "How much would you like to allocate to Group Account in GREEN GAME?" and the program will allow you to enter in your number choices. When you are finished making your choices, click "Submit". You can allocate as much or as little of your francs as you like in each period, but remember that the total francs you choose to allocate must not exceed 160 francs in each period. You keep any francs which you do not allocate; therefore, your earnings are the sum of the francs you decided to keep, your earnings from BLUE GAME, and your earnings from GREEN GAME.

\section{BLUE (GREEN) GAME}

Below, we will read instructions for the BLUE GAME. However, the rules for the BLUE GAME and the GREEN GAME are exactly the same. The only difference is that all three participants you are matched with for the GREEN GAME are different from the participants you are matched with for the BLUE GAME.

Each period you will decide how much of your endowment you want to allocate to a Group Account. You may allocate any integer number of francs between $\mathbf{0}$ and $\mathbf{1 6 0}$, as long as the total number of francs used for allocations in both games does not exceed 160. After all participants have made their decisions, your outcome for the period is calculated.

Your period outcome from BLUE GAME depends on the total number of francs allocated to the Group Account by all 4 group members (including you). In particular, your earnings from the Group Account are 40 percent of the total allocation of all 4 group members (including you) to the Group Account. Therefore, for every franc you allocate to the Group Account, you increase the total allocation to the Group Account by 1 franc. Therefore, your earnings from the Group Account rise by $0.4 \times 1=0.4$ francs. And the earnings of the other group members also rise by 0.4 francs each, so that the total earnings of the group from the Group Account rise by 1.6 francs.

In summary, your period outcome in BLUE GAME is determined as follows:

$$
\begin{aligned}
& \text { BLUE GAME Outcome = (earnings from Group Account })- \text { (your allocation to the Group } \\
& \text { Account })= \\
& =0.4 \times \text { (allocation of } 4 \text { group members to Group Acct. })-(\text { your allocation to Group Acct. })
\end{aligned}
$$

Example: Suppose that you allocated 40 francs to the Group Account and that the other three members of your group allocated a total of 120 francs. This makes a total of 160 francs in the Group Account. In this case each member of the group receives earnings from the Group Account of $0.4 \times 160=$ 64 francs, which is also each member's period outcome in the BLUE GAME. 


\section{TOTAL EARNINGS}

After you choose how much to allocate to the Group Account in the BLUE GAME and how much to allocate to the Group Account in the GREEN GAME, the remainder of your 160 francs will be allocated to your Individual Account. Your earnings from the Individual Account equal to the francs that you keep for yourself and do not depend on the decisions of others. Therefore, for every franc you keep for yourself in your Individual Account, you earn 1 franc.

Your total earnings will be converted to cash and paid at the end of the experiment if the current period is the period that is randomly chosen for payment. Your total earnings for each period will be calculated as:

Total Earnings $=(160)+($ Outcome from BLUE GAME $)+($ Outcome from GREEN GAME $)=$
Which is the same as
$=160+($ Earnings from Group Account in BLUE GAME $)-($ allocation to Group Account in
BLUE GAME)
$+($ Earnings from Group Account in GREEN GAME)-(allocation to Group Account in GREEN
GAME)

\section{OUTCOME SCREEN}

At the end of each period, your allocation, the sum of all allocations in your group for each of BLUE GAME and GREEN GAME, and the outcome for each of BLUE GAME and GREEN GAME are reported on the outcome screen. The computer will also display your income from the individual account and your total earnings for the period. Once the outcome screen is displayed you should record your results for the period on your Personal Record Sheet under the appropriate heading.

At the end of the experiment $\mathbf{2}$ out of $\mathbf{2 0}$ periods will be randomly selected for payment. Your earnings for these two periods will be converted to U.S. dollars at the end of the experiment at the rate of 25 francs $=\$ 1$. 